MARTI PALLA ${ }^{1}$

DOI: 10.15290/cr.2019.24.1.07

Newbold College of Higher Education,

United Kingdom

ORCID ID: 0000-0002-4480-8437

\title{
Preschool children's sensitivity to the generic and non-generic distinctions
}

\begin{abstract}
Generics convey generalizations about kinds e.g., "fish swim," or "birds have wings". In contrast, non-generics express facts about specific individuals or groups of individuals, e.g., "my cat has caught two mice" or "two birds are sitting in that tree". To interpret utterances generically or non-generically, speakers of Polish use morphosyntactic features (e.g. determiners, plurality, tense and aspect), contextual cues, as well as world knowledge (Grzegorczykowa 2001; Karczewski \& Wajda 2015; Karczewski 2016). The aim of the present study is to determine the extent to which preschool children are sensitive to one morphological cue in particular, i.e. the demonstrative determiner te (these) in Polish.
\end{abstract}

Keywords: generic sensitivity, generics and non-generics, morphological cue, demonstrative determiner.

\section{The definition of generic and non-generic cues}

Generic and non-generic distinctions are made on a regular, everyday basis in speech. Generalizations about categories serve the purpose of relaying information on their properties and communicating elementary, uncomplicated principles, such as the simple statement "Fish swim". These predictions are established to create linguistic comprehension, utilizing context and prior knowledge to assign attributes to particular categories of, specifically, artifacts or animals (Gelman et al. 2010).

Generic cues express categories that focus on various classes differentiated by speech. They are used in every language, as all languages provide the means to express generics, although the ways in which they are transferred differ. They are generally used to imply properties to distinct objects, in particular contexts, and the concept of generic and non-generic distinctions is used in conversation for the purpose of relaying subjective beliefs, as well as fundamental truths. According to Gelman, generic statements can be made about general categories of objects, without referring to a specific entity or an exception to a particular category. A generic utterance expresses the universal qualities of a given class, pointing to a factor that characterizes a certain group in an indicated

1 Address for correspondence: Newbold College St Mark's Rd, Bracknell RG42 4AN, Great Britain, E-mail: marti. palla@wp.pl 
context. They can be construed with an understanding of social meaning, linguistic background and with a scope of common knowledge, which can be combined for the purpose of fully understanding an utterance (Gelman et al. 2010).

An example of this can be specifying a class of entities, and expressing the properties which are invariable, universal and permanent throughout the course of time. A generic utterance such as "trees have leaves" is not limited to only a specific situation or context, but is rather adjoined to an extensive and established fact that is accepted by the social standards of normalcy, excluding deviations. Such utterances are known as "kinds" (Cimpian et al. 2008). A "kind" has shared features which may appear to be obvious, even if they are hidden and cannot be directly observed. An example of this can be the utterance "some trees have needles instead of leaves".

Generic and non-generic distinctions are a linguistic tool that constitutes an important element of conversation to which children are exposed at a very early age. While they hear generics in speech regularly, they start to put the concept to use by the age of 2 , and learn the initial differentiations between generic and non-generic cues during the time they are in preschool.

While the results of the experiment conducted for the purpose of this article show that the ability to interpret generics increases with age, some studies performed on both children and adults had similar results, even though different mechanisms are used by these age groups in the process. An example of this is a study in which adults were asked to interpret a statement and relay information on the particular category (Cimpian et al. 2010). In the study, adults were asked to provide an evaluation of how much of each particular group was included in the statement about a target feature. The initial generic statement that was given was "Lorches have purple feathers". The answer given by the adults on the percentage of lorches having purple feathers was in the range of $95 \%$, meaning that the feature was thought to apply to nearly all of the members of the group. The children included in the study also arrived at a similar conclusion to the adults, as they interpreted the generic statement as referring to all, or almost all, of the "lorches". The results of this task provide proof that generic and non-generic distinctions can be used as a tool in understanding how children view the world from a linguistic perspective. They can provide a basis for research on a child's linguistic development by comparing such results to those of mature test subjects, which in turn may contribute to advances in the field of child education (Cimpian et al. 2010).

\section{Sensitivity to immediate linguistic context}

In order to correctly understand the differentiations between generic and non-generic cues, context must be provided for a child to assign the object to a new category or "kind" (Brandone et al. 2013). Similarly, for one to assign certain properties to a particular object, they have to be familiar with it and have prior knowledge about it. However, a limited amount of knowledge on a certain subject may lead to more prevalent generalizations. An example of this is a study done by Gelman, Ware and Kleinberg in 2010, who found that by using generic language to describe a new category called the "Zarpies", preschoolers believed that the given characteristics were attributed to the entire class. A statement such as "Zarpies eat a lot of popcorn", or "Zarpies have striped, orange 
fur" had the same effect as the earlier study involving "lorches". The tested preschoolers assigned the properties that they heard about the "Zarpies" to the entire category, later assuming that one "Zarpie" feature would be the same for all of them. These tasks conclude that upon receiving information on one specimen of a given category, the children studied were likely to consider the entire category to have the same feature.

The same theory proves to be consistent when conducting tasks on other groups of children and adults, as was done by Brandone and Gelman in 2009. While people have varying levels of knowledge on artifacts and familiar items, more generic utterances were produced when describing new categories of animals that have been created for the purpose of the studies. While characterizing the labelled, new categories of animals, both adults and children described them generically, by stating that the entire category has the same features as the specimen shown to them. An example of this would be seeing a blue bear called a "Blear" and stating that "Blears are blue", rather than saying that "This Blear is blue". Interestingly, new categories of artifacts invoked a different response, as the subjects had a tendency to describe them generically significantly less often than the new categories of animals. This, however, is likely caused by "domain differences", which show that children, similarly to adults, view artifact categories as less consistent and invariable than animal categories.

A study that was conducted by Cimpian and Cadena in 2010 included forty-eight participants between 4-5 years of age, who were divided into two groups for the purpose of the task. The children were shown pictures of abstract articles that were labelled and described to them (e.g. "This is a dunkel. Dunkels are sticky."). They were then asked to explain the purpose of the mentioned feature in the specified artifact (e.g. "Why do you suppose dunkels are sticky?"). The results of the study confirmed that the 5 year old participants were able to correctly use generic and non-generic distinctions in referring to functional properties of the artifacts more successfully than the younger participants.

Children have been proven to be capable of recognizing and using generic forms from an early age, but generic and non-generic distinctions pose a problem to beginning learners. The idea of generics is fathomable to adults, but is a complex concept for children to understand and may cause difficulties, as it is an abstract approach (Sobel et al. 2015). The notion of generics is a challenging concept to grasp, especially considering that no language provides strict rules that are applied to the construction of generic statements, and only specific representations of a category can be presented in conversation when indicating them. There are no concrete signifiers of generic forms in linguistics, and in order to evoke a distinct example of a kind, the same form must be used when describing an entire category. This can be observed in the examples below, which have been created on the basis of Gelman's Generic Language in Parent-Child Conversations:

1. Psy maja cztery nogi. / Psy czekaja na resztki jedzenia.

'Dogs have four legs.' / 'Dogs wait for scraps.'

2. Słoń pije wodę za pomoca trąby. / Słoń uciekł z zoo.

'An elephant can drink water by using its trunk.' / 'An elephant escaped from the zoo.' 


\section{Wiele osób je płatki na śniadanie. / Płatki były rozsypane po całej podłodzie.}

'Cereal is what many people eat for breakfast.' / 'Cereal was scattered across

the entire floor.'

The sentences above are examples of why sentence construction does not strictly determine the generics of a statement, therefore complicating the process by which learners can effectively understand and master the unapparent fundamentals of generic and non-generic cues. Each of the sentences contains a noun phrase (NP), but only the first sentences are generic, with the second ones having non-generic distinctions. Young children are capable of understanding the basics of generics by the age of 3-4 and are able to provide generic and non-generic statements with an understanding of their differences (Gelman 2003).

The content of generics may vary, including artifacts (e.g. "Doors have knobs"), animals ("Spiders have many legs") and food ("Ice cream is cold"). They can also include social kinds (e.g. "Poles are very hospitable") and inanimate natural categories ("Carbon can be found in the environment”). Surprisingly, generics are not consistently applied to every category, as it has been observed in records of everyday conversation conducted by adults that some kinds are considered to be more generic than others.

For example, the category of animals is most often referred to in a generic manner, even species that speakers are familiar with. In comparison, categories such as artifacts, food and inanimate objects are spoken of in more non-generic terms. Young children, however, are reported to have far less instances of assigning non-generic properties to generic categories, likely assuming them to be individuals rather than representations of entire kinds. The reason for this is unknown, proving that there are still many aspects of generic and non-generic cues left to uncover and research in the scope of linguistics (Yoshida et al. 2005).

Generic expressions are conveyed through the use of plurals (e.g. Laptops have built-in keyboards/The poor are often forgotten) and singulars (e.g. A chair has four legs/The dolphin is considered to be an intelligent mammal). Non-generic statements also utilize plurals (e.g. More laptops are sold online than in-store/The poor women searched for jobs) and singulars (e.g. A chair was brought in by the workers/The dolphin swam past them). In some cases, in order to differentiate generic and non-generic utterances, an additional morphosyntactic cue is the basis for the analysis and proper understanding of a statement. These cues include the use of tenses, determiners, number (singular/plural) and other pragmatic cues.

Children are, from the very beginning of their existences, surrounded by a substantial variety of objects which fall into the category of "artifacts". The wide array of artifacts poses the difficulty of understanding individual purposes that relate to their exteriors. Children, in learning about these objects, must connect their appearances to their functions and assign them to categories, while also discerning which properties have been deliberately applied (e.g. the handle of a cup), and which have only decorative purposes (e.g. designs on a doorknob). In order to appropriate them into categories, children have the challenge of learning about the functions of various arti- 
facts and how they are related to other objects. While some properties may be discovered by them through context and observation (e.g. when they see someone use a spoon to eat soup), others may require verbal descriptions (e.g. when they are told that a printer needs ink to work). A child must also learn the meaning of general properties, e.g. that thin objects are most often easy to tear, or that light, porous items can float on top of water. There are many specific elements that play a role in perspective, and discovering how to place certain factors into categories can prove to be difficult, especially for younger children. With age, however, there is progress and the ability to discern such contingencies increases (Gelman 2008).

A study conducted by Karczewski and Buivolova (2015) focused on extralinguistic cues in generic and non-generic meaning, one of the aims being to examine Russians' interpretations of the usage of a singular NP along with two exemplars of a category, as compared to their interpretations of the usage of a plural NP in the presence of two exemplars of a category. The study, which consisted of 162 Russian participants, utilized pictorial stimuli portraying animals with atypical features (e.g. a camel with a green hump). Each participant was shown a picture and asked a question to determine if they made distinctions between generic and non-generic meaning (e.g. "Here is a camel. Do camels have green humps?"). The questions were posed in the singular-singular, singular-plural, plural-singular and plural-plural conditions. The answers (each "yes" and "no") were established as either generic or non-generic. The provided results of the study cover the answers given in each condition, e.g. that participants would give non-generic answers to the singular-plural condition.

The purpose of the following studies, which have also utilized pictorial stimuli and have put a focus on generic and non-generic cues, is to reach a better understanding of the linguistic process of 3-6 year-olds regarding the nature of generic and non-generic distinctions. The tasks will be based on distinguishing whether or not preschool children are capable of observing such cues in everyday speech and if they can independently utilize them in communication.

One of the aspects of the studies will be observing if the children detect a difference between generic and non-generic utterances, with visual aids that will make the process reliable and balanced for the test subjects as well as suited to their age range. The study will serve as a basis to further understand the function of generic and non-generic cues and whether differentiating them poses difficulties for children in the specified age group of 3-6 years.

\section{A general overview of the conducted tasks}

The studies in this article have been conducted in a preschool in Poland (a Montessori Preschool in Białystok), among children between the ages of 3-6. Sixty pre-schoolers participated in the study (thirty-four of them were girls), with fourteen 3-year-olds, fifteen 4-year-olds, sixteen 5-year-olds and fifteen 6-year-olds. All of the children were European, from a range of socioeconomic backgrounds, with Polish serving as their first language. The tasks were conducted in Polish. This specific age range was chosen so as to gain a perspective on the differentiating capabilities of preschoolers in this particular aspect, in order to compare the results to other studies conducted in this spectrum. 
Before the task began, preschoolers between the ages of 3-6 were asked to come in one by one and to sit in front of the examiner. After the children introduced themselves, they were told that they were going to play a game. Each of the preschoolers was then asked to look at the picture shown to them and perform the specified tasks. Four consecutive tasks were conducted, each lasting from one to two minutes. The testing sessions were conducted in quiet rooms in the preschool of the children participating in the study. The pictures used for the tasks were drawn by Anna Bakłażec and provided by Daniel Karczewski.

The aim of the study was to determine the extent to which preschool children are sensitive to one morphological cue in particular, i.e. the demonstrative determiner te (these) in Polish. The general premise of the tasks, as well as their design, was to evaluate preschooler's sensitivity and usage of morphosyntactic features in a variety of studies. Four tasks were conducted in order to gain a wide perspective and a plausible result to conclude the thesis, as one or two would be scientifically insufficient to be considered an authentic outcome.

\section{Study 1}

Study 1 was made up of a series of questions, which deduced the children's capability to differentiate generic and non-generic categories. The children were asked questions which were accompanied by pictures. A picture of two frogs with tails was shown with questions 1 and 2 (Picture 1), and a picture of three rabbits with one ear each with questions 3 and 4 (Picture 2).
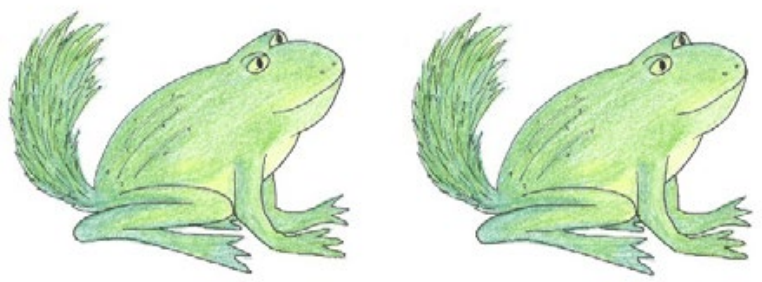

Picture 1.

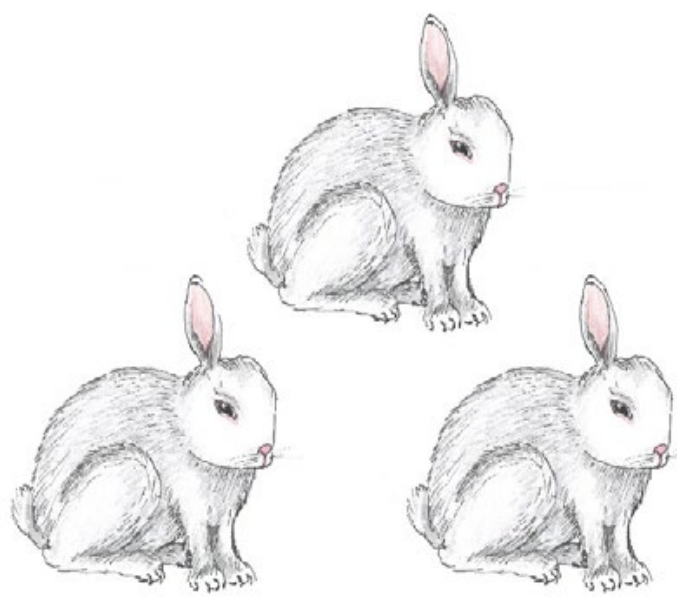

Picture 2. 
The questions were as follows:

1. Czy żaby maja ogony? 'Do frogs have tails?'

2. Czy te żaby maja ogony? 'Do these frogs have tails?'

3. Czy te króliki maja po dwoje uszu? 'Do these rabbits have two ears?'

4. Czy króliki maja po dwoje uszu? 'Do rabbits have two ears?'

The purpose of this phase was to introduce the children to the following tasks, while allowing the opportunity to observe whether they are able to discern a difference between the posed questions, which were accordingly related to the accompanying pictures. Questions 1 and 4 reflected generic properties, while questions 2 and 3 were non-generic. In this task, children had the opportunity to observe a pattern of generic vs non-generic. While being shown a picture, they could either assume the questions to have been repeated two times each and not notice a difference between them, or observe that the addition of the word "these" had a specific meaning in the given context.

The study was conducted individually on fourteen 3-year-olds and fifteen 4-year-olds. They were able to correctly differentiate generic and non-generic properties $49 \%$ of the time (with $42 \%$ within the group of 3-year-olds and 56\% within the group of 4-year-olds). The percentage has been calculated by accounting for all of the correctly given answers in contrast with those that were incorrect. If a child, for example, was able to answer the generic question "Do frogs have tails?" with "No.", this signified that they could observe and apply their knowledge of generic properties, being conscious of the fact that the two frogs with wings in the picture of front of them were an exemption from the general concept of the visual appearance of this particular category. In order to avoid miscommunication, the second picture had three rabbits with one ear each, so that the child could answer without any confusion.

The study was identically conducted on sixteen 5-year-olds and fifteen 6-year-olds. The children in both of these age groups were able to correctly differentiate generic and non-generic properties $64 \%$ of the time (with $60 \%$ within the group of 5 -year-olds and $68 \%$ within the group of 6 -year-olds).

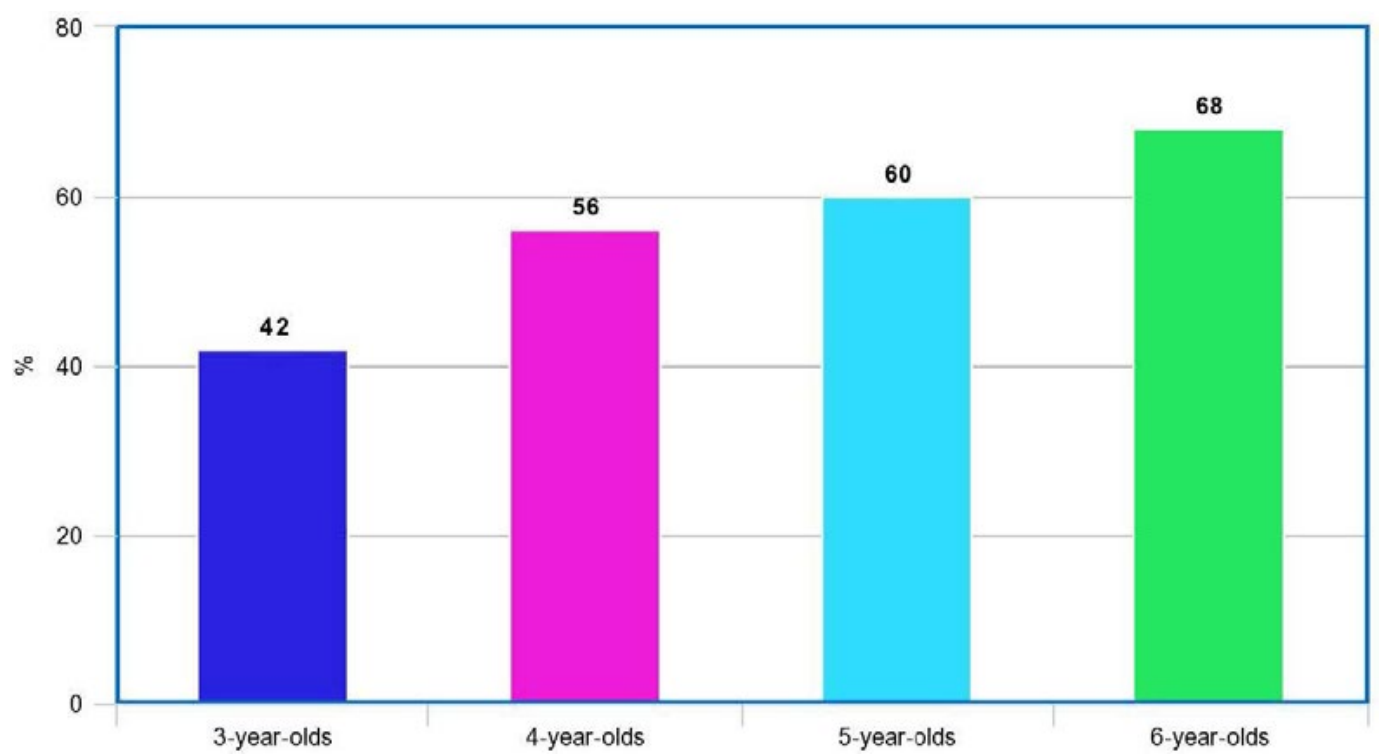

Figure 1. The results of Study 1 


\section{Study 2}

In Study 2, the children were individually asked open questions. They were each told that they would now play a game that included a dragon puppet named "Basia". Each of them was instructed that when Basia was on the table, she could both hear and see them and what they were saying. However, the rules were to change whenever Basia was "sleeping" under the table, because then she would not be able to see or hear the child. The child's task was to tell the puppet about everything that they had learned when the toy was hidden. The reason for this method was to determine whether the child would be able to use morphosyntactic features while describing what they have seen in the picture, as they were told to assume that the dragon did not know what was on the picture and would need to be informed of it. If the dragon had remained on the table, the child would have been more likely to repeat what they had just heard, instead of processing it in order to relay it to Basia. Once Basia the puppet was hidden, the child was shown a succession of pictures with the accompanying statements:

1. Te żyrafy mają krótkie szyje. 'These giraffes have short necks.'

2. Owce sa białe. 'Sheep are white.'

3. Te ryby maja sierść. 'These fish have fur.'

After each statement and shown picture, the puppet was brought out and the child was asked to tell Basia the dragon what they had just learned. The child then proceeded to tell the puppet what they had seen - while the answers varied, the most uniform refrained to either an inclusion, or exclusion of the word "these", indicating whether the child had understood the genericness/nongenericness of the statement. Upon being shown a picture of two green sheep and being told that "Sheep are white", the child could answer by including a generic property, a non-generic property or a combined statement ("These sheep are white", which would be inconclusive, as neither of the sheep in the picture were white). The third possible answer was however not given by any of the studied children throughout the course of the task.

The fourteen 3-year-olds and fifteen 4-year-olds were able to correctly differentiate generic and non-generic properties $40 \%$ of the time (with $30 \%$ within the group of 3 -year-olds and $51 \%$ within the group of 4 -year-olds).

The sixteen 5-year-olds and fifteen 6-year-olds were able to correctly differentiate generic and non-generic properties $67 \%$ of the time (with $60 \%$ within the group of 5 -year-olds and $75 \%$ within the group of 6-year-olds). 


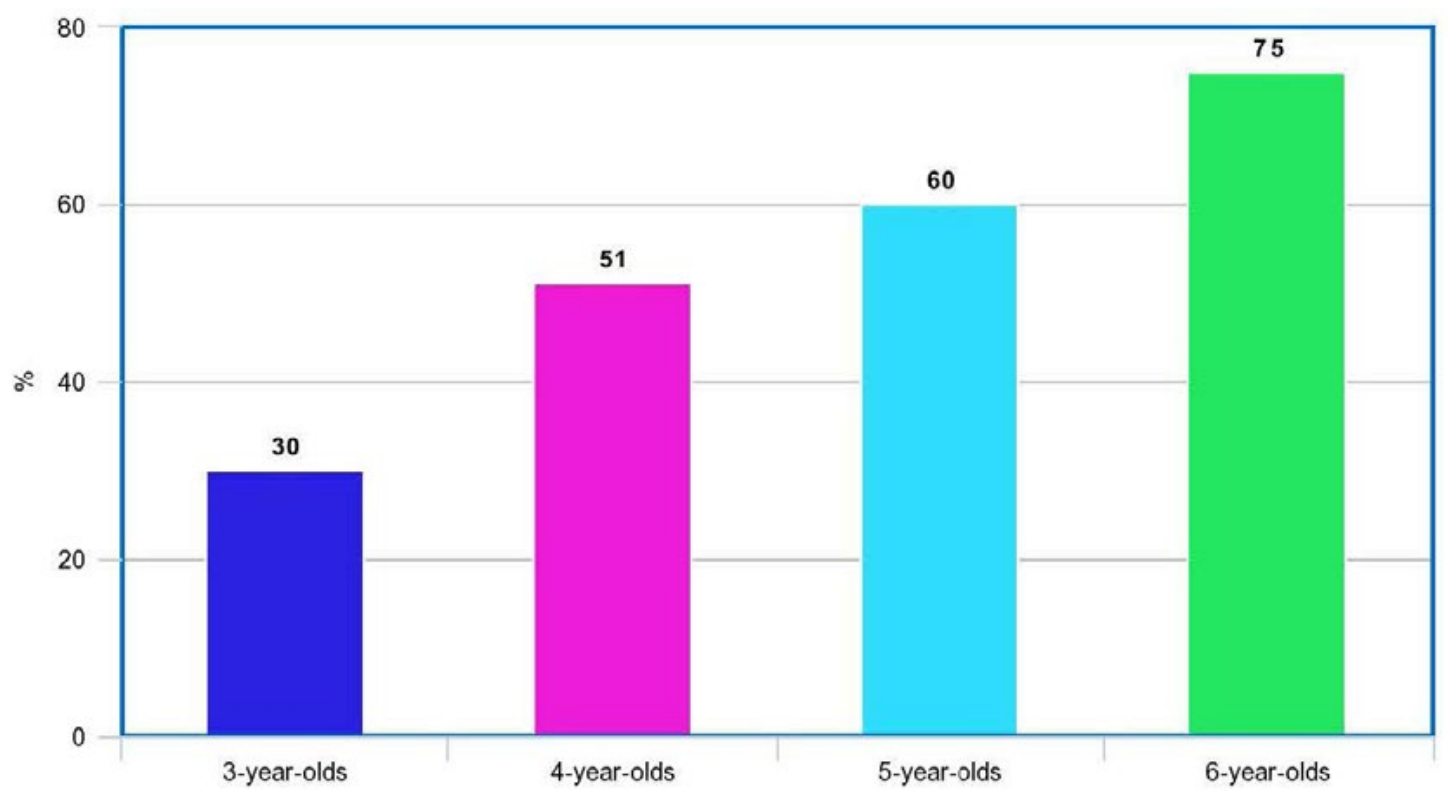

Figure 2. The results of Study 2

\section{Study 3}

During the third study, children were asked direct questions, while being shown assorted pictures. The questions were as follows:

1. Ile nóg maja bociany? 'How many legs do storks have?'

2. Jakiego koloru sq owce? 'What colour are sheep?'

3. Ile nóg maja te psy? 'How many legs do these dogs have?'

The children could have based their answers either on the pictures they saw in front of them, on the utterance that they heard, or on a combination of both. A correct answer to e.g. question 1 of Study 3 would however be based on common knowledge that the child possesses, and whether or not they know how to assign/exclude the objects in the picture from a general category, which would show a sensitivity to generic and non-generic distinctions.

The fourteen 3-year-olds and fifteen 4-year-olds were able to correctly differentiate generic and non-generic properties $38 \%$ of the time (with $23 \%$ within the group of 3 -year-olds and $53 \%$ within the group of 4 -year-olds).

The sixteen 5-year-olds and fifteen 6-year-olds were able to correctly differentiate generic and non-generic properties $68 \%$ of the time (with $66 \%$ within the group of 5 -year-olds and $70 \%$ within the group of 6-year-olds). 


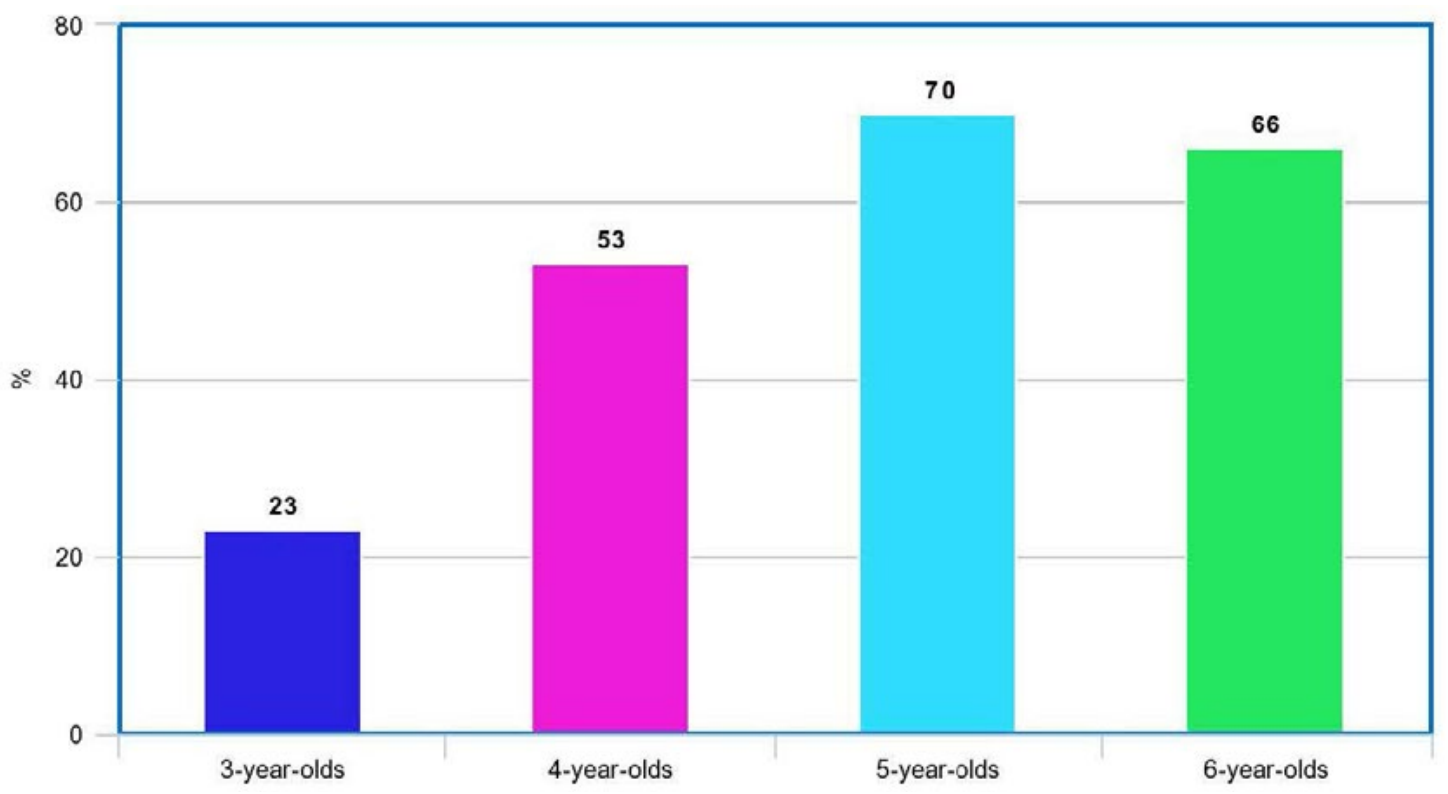

Figure 3. The results of Study 3

\section{Study 4}

During the final study, children were asked "yes or no" questions. The questions were as follows:

1. Czy tygrysy maja rogi? 'Do tigers have horns?'

2. Czy te krowy maja pazury? 'Do these cows have talons?'

3. Czy świnki sq niebieskie? 'Are pigs blue?'

Study 4 was straightforward, and required the child to answer with "yes or no" as instructed, or with a full sentence. Answers such as "No, but these ... have/are ..."/"Nie, ale te ... mają/są ..." were also accepted, as they indicated a sensitivity to generic and non-generic distinctions.

The fourteen 3-year-olds and fifteen 4-year-olds were able to correctly differentiate generic and non-generic properties $40 \%$ of the time (with 33\% within the group of 3 -year-olds and $48 \%$ within the group of 4 -year-olds).

The sixteen 5-year-olds and fifteen 6-year-olds were able to correctly differentiate generic and non-generic properties 59\% of the time (with 52\% within the group of 5-year-olds and $66 \%$ within the group of 6-year-olds). 


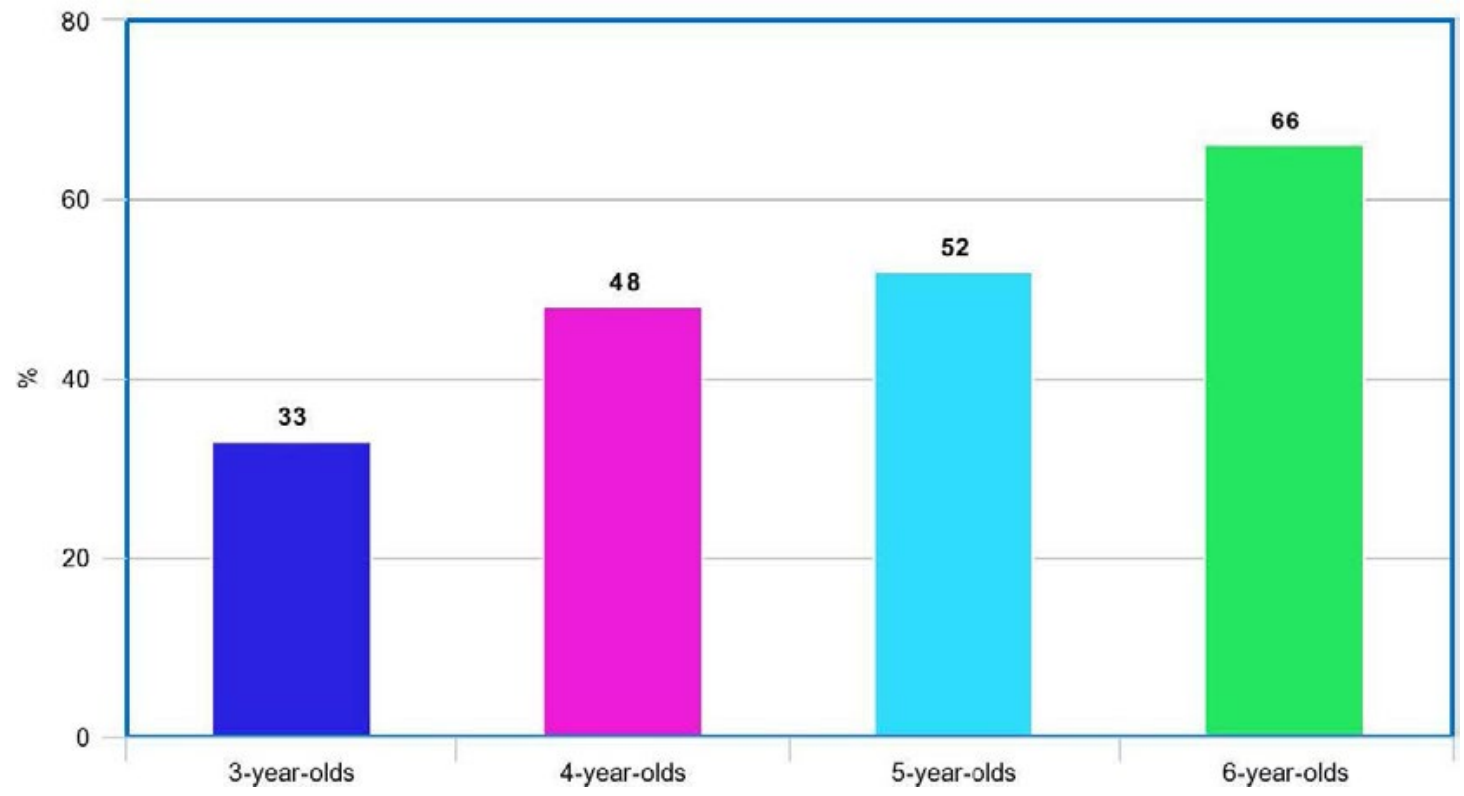

Figure 4 . The results of Study 4

\section{Results}

Overall, the four studies point to a significant difference in the sensitivity to generic and nongeneric distinctions between 3- and 4-year-olds collated with the results of those of the 5-and 6 -year-olds. While the results of the 3-and 4-year-olds calculated to a total of $42 \%$ (with $32 \%$ of 3-year-olds and $48 \%$ of 4 -year-olds answers correctly differentiating generic and non-generic properties), the 5 - and 6-year-olds achieved a result of $65 \%$ (with $60 \%$ of the 5 -year-olds and $70 \%$ of the 6-year-olds answers correctly differentiating generic and non-generic properties).

The percentage of answers indicating generic and non-generic sensitivity rises with each year, proving that recognizing such properties grows stronger with progressing age. The only drop observed during the course of the studies takes place in Study 3, in which the tested 5-year olds reached $70 \%$ of generic sensitivity, while 6 -year-olds had only $66 \%$.

The question which had the most incorrect answers in Study 3 was the first question ("How many legs do storks have?"), in which children were shown a picture with two storks that each had three legs. It is worth noting that amongst the 5-year-olds, only two of them did not provide an answer indicating awareness of generic/non-generic properties, while out of the fifteen tested 6-year-olds, only six answered correctly. The two 5-year-olds that answered incorrectly replied that "Storks have four legs", while the nine of the 6-year-olds said that "Storks have three legs". The reason for why the 5-year-olds provided an answer that was not correct for either the picture or the utterance has not been researched in depth in this article, but may serve as a basis for further speculation - though one of the reasons may be a miscalculation among the children that were attempting to answer the question by focusing only on what they saw in the picture. 6-year-olds however, have a vaster knowledge of numbers than the previous group and may have, in easily 
counting the number of the storks' legs, given the answer that would showcase their abilities to count, rather than focusing on linguistic properties.

In Study 1, the answers of the specific age groups were relatively uniform. Throughout the course of the tasks, a tendency to answer questions involving numbers has been generally observed to have a higher rate of answers discerning generic/non-generic distinctions, than e.g. questions involving colours in the age group of 4, 5, and 6 years of age (excluding question 1 in Task 2 , which had the best results in the age range of 4-5). The questions "Do rabbits have two ears?" and "Do these rabbits have two ears?" invoked a sum of $63 \%$ of correct answers among these age groups, while the questions "Do frogs have tails?" and "Do these frogs have tails?" were answered with a sensitivity to generics only $51 \%$ of the time.

Although this could be credited to the order of the questions (the questions concerning the frogs with tails being before those about the rabbits with one ear each), this does not explain the similar effect of the question "How many legs do these dogs have?", which was the final question in Task 3. This question, with $60 \%$ of correct answers in the sum of the age groups, is significantly higher than that of the other two questions in the same task (question 1 having 50\% and question 2 having 51\%).

While to some, this conclusion may appear to be inconclusive or the result of chance, as may be the case in the tested spectrum of ages, numbers may have a role in the way that children perceive linguistic forms. Focusing on numeral properties may help in increasing the speed of the process of linguistic acquisition among preschool children, as at the time of the conducted tasks, they are also in the process of learning about numbers and Maths.

The question that received the lowest overall percentage in each age group was in Study 4: "Do these cows have talons?". This may seem surprising, as Study 1 had a fairly high average of generic/ non-generic responsiveness, also including questions of a similar structure and animals with unordinary traits. The reason for this may lie in the child assuming that there is a pattern in this category, but in such an event, Study 1 would have a similar effect in the answer pattern (which it did not). The trait is not one that would normally be assumed to be universal for the species in the picture, and children do not have a problem with understanding the word "talons" in Polish. This too is left for further studies.

\section{Acknowledgements}

I would like to sincerely thank and acknowledge Daniel Karczewski for his support and for providing the pictures used for the task, which allowed the experiment to take place, as well as Anna Bakłażec, who was their author. I would also like to extend my sincere thanks to the principal of the Montessori preschool in Białystok on Świętego Mikołaja 9, Ewa Gutowska, for allowing me to conduct studies for this paper, as well as to Katarzyna Walczak for her help throughout the entire process.

\section{References}

Brandone, A. C. \& Gelman, S. A. 2013. Generic language use reveals domain differences in young children's expectations about animal and artifact categories. Cognitive Development 28(1): 63-75. 
Cimpian, A. \& Markman, E. M. 2008. Preschool children's use of cues to generic meaning. Cognition 107: 19-53.

Cimpian, A. \& Cadena, C. 2010. Why are dunkels sticky? Preschoolers infer functionality and intentional creation for artifact properties learned from generic language. Cognition 117: 62-68.

Cimpian, A. \& Cadena, C. 2011. The generic/non-generic distinction influences how children interpret new information about social others. Child Development 82(2): 471-492.

Cimpian, A. \& Scott, R. M. 2012. Children expect generic knowledge to be widely shared. Cognition 123: 419-433.

Gelman, S. A. \& Goetz, P. J. 2008. Generic Language in Parent-Child Conversations. In: C. Fisher (ed.), Language Learning and Development. Michigan: University of Michigan.

Gelman, S. A. \& Goetz, P. J. 2003. Preschool Children Use Linguistic Form Class and Pragmatic Cues to Interpret Genetics. Child Development 74(1): 308-325.

Graham, S. A. \& Nayer, S.L. 2011. Two-year-olds use the generic/nongeneric distinction to guide their inferences about novel kinds. Child Development 82 (2): 493-507.

Grzegorczykowa, R. 2001. Wprowadzenie do semantyki językoznawczej. Warszawa: Wydawnictwo Naukowe PWN.

Hollander, M. A. \& S. A. Gelman. 2002. Children's Interpretation of Generic Noun Phrases. Developmental Psychology 38 (6): 883-894.

Karczewski, D. \& Wajda, E. 2015. Perceptions of different syntactic forms of generics: An experimental study. Białostockie Archiwum Językowe 15: 233-245.

Karczewski, D. \& Buivolova, O. 2015. Sensitivity to extralinguistic cues to identify generic and non-generic meaning. Crossroads. A Journal of English Studies 10: 4-14.

Karczewski, D. 2016. Generyczność w języku i w myśleniu. Studium kognitywne. [Genericity in language and thought. A cognitive study]. Kraków: Universitas.

Sobel, D. M. \& Jipson, J. L. 2015. Cognitive Development in Museum Settings: Relating Research and Practice. London: Routledge.

Yoshida, H. \& Smith, L. B. 2005. Linguistic Cues Enhance the Learning of Perceptual Cues. Psychological Science 16(2): 90-95.

\section{$* * *$}

Marti Palla holds a BA in English Philology and is pursuing an MA in Translation Studies. Her research interests include: cognitive linguistics and language acquisition. 